\title{
Barriers to physical activity among cancer pediatric cancer patients and survivors: a scoping review
}

\author{
Jean Augusto Coelho Guimarães ${ }^{1}$ (D), Paulo Henrique Guerra ${ }^{2,3}$ (D), Deisy Terumi Ueno ${ }^{1}$ (D), \\ Letícia Aparecida Calderão Spósito $^{1}$ (D), Emerson Sebastião ${ }^{4}$ (D), Priscila Missaki Nakamura ${ }^{1,5}$ (D) \\ ${ }^{1}$ Universidade Estadual Paulista, Instituto de Biociências, Programa de Pós-Graduação em \\ Ciências da Motricidade, Departamento de Educação Física, Rio Claro, SP, Brazil; \\ ${ }^{2}$ Universidade Federal da Fronteira Sul, Chapecó, SC, Brazil; ${ }^{3}$ Universidade de São Paulo, \\ Grupo de Estudos e Pesquisas Epidemiológicas em Atividade Física e Saúde, São Paulo, SP, \\ Brazil; ${ }^{4}$ Northern Illinois University, Department of Kinesiology and Physical Education, Health \\ and Exercise Research Group, Illinois, United States; ${ }^{5}$ Instituto Federal de Educação, Ciência e \\ Tecnologia do Sul de Minas Gerais, Muzambinho, MG, Brazil.
}

Associate Editor: Romulo A. Fernandes (D), Universidade Estadual Paulista "Júlio de Mesquita Filho”, Presidente Prudente, SP, Brazil. E-mail: romulo_ef@yahoo.com.br.

\begin{abstract}
Aim: The present scoping review aims to provide an overview of barriers to PA reported by pediatric cancer patients undergoing treatment as well as after treatment. This study further aims to describe and discuss the instruments used for assessing barriers in this population. Methods: Article search was performed in common medical databases and yielded five original research articles. Results: The included articles reported barriers to PA that can be grouped into the following categories: individuals, physical, environmental, and treatment. Among the instruments used to assess barriers to PA, it was observed that questionnaires and interviews are commonly adopted. This review underscores a paucity of studies in this area. Conclusion: A comprehensive understanding of barriers to PA in the pediatric cancer population is paramount for the development of tailored strategies and interventions aiming to promote PA in this under-researched group. In addition, future studies must adopt a mixed-methods approach, longitudinal design with specific instruments in the pediatric cancer population.
\end{abstract}

Keywords: oncology, pediatric, barriers, physical activity.

\section{Introduction}

Pediatric cancer is characterized by a set of rare neoplasms, with moderate incidence ${ }^{1}$ and a high risk of mortality ${ }^{2}$. There is evidence suggesting that insufficient amounts of physical activity (PA) (i.e., less than $60 \mathrm{~min}$ of moderate-to-vigorous PA daily) is an independent risk factor $3^{3-5}$ both for cancer onset as well as for other conditions after treatment, such as for overweight, obesity ${ }^{6}$, cardiovascular diseases ${ }^{7}$, and musculoskeletal deficits ${ }^{8}$. However, despite the well-known physical ${ }^{9}$ and psychosocial ${ }^{10}$ benefits associated with regular PA a significant portion of pediatric cancer patients (i.e., 4-19 years) undergoing treatment and/or cancer survivors do not reach the current recommendations of PA and are less active than their peers without the disease ${ }^{11,12}$.

A wide range of factors related to insufficient amounts of PA in this population is described in the literature. Factors negatively impacting the ability of the individual to partake in physical activity have been called barriers. Barriers to PA can be defined as factors that pre- vent or make it difficult to start or maintain regular PA. Such factors are known to be complex and multifactorial in nature ${ }^{13}$. A large array of barriers has been reported to be associated with reduced amounts of PA in pediatric cancer patients, including but not limited to fatigue, risk of infection, pain, low self-esteem, lack of time, poor school performance, and lack of medical advice on PA for adolescents and family members ${ }^{14}$.

Identifying and understating barriers to PA, in different populations, are crucial for the development of tailored strategies and interventions focusing on PA promotion ${ }^{15}$. In the context of barriers to PA in the pediatric cancer population (i.e., undergoing treatment and cancer survivors) some contributions can be observed in the literature $^{16}$. However, to the best of our knowledge, no study has attempted to provide an overview/summary of the available literature on this matter (i.e., scoping review). This is important because, given the heterogeneity of previous studies, an overview of the existing findings and aspects of the methodology adopted (i.e., instruments 
would provide a better understanding of the most frequent barriers to PA in this population and provide helpful and valuable information for future studies addressing this topic) may help identify potential targets for intervention and better guide future studies in this area.

In view of the important role played by PA as a complementary therapy for cancer treatment ${ }^{17}$ and the possibility of supporting actions focusing on health promotion, the present study aimed to conduct a scoping review of barriers to PA in the pediatric cancer population, as well as to examine the methods/instruments used to assess such information. Scoping review is a relatively new approach to evidence synthesis and differs from systematic reviews in its purpose and aims. Although unclear about the term systematic, these reviews have common points like research question, search strategy, inclusion and exclusion criteria, selection methods, quality/risk of bias, data analysis, and synthesis allowing reproducibility ${ }^{18}$. However, scoping review is conducted to provide an overview of the available research evidence without producing a summary answer to a discrete research question ${ }^{19}$.

\section{Methods}

This scoping review was conducted according to systematic principles (Supplement 1) found at the Preferred Reporting Items of Systematic Review and Metaanalyzes - PRISMA ${ }^{20}$ and registered in the International Prospective Register of Systematic Reviews (CRD42018090447).

\section{Study design and eligibility}

It was previously defined that this scoping review would include: a) original research articles; b) research studies using observational and experimental designs; c) research studies published in English, Portuguese and Spanish; and d) research studies that included pediatric population during and/or after cancer treatment. It is important to highlight that research studies including comprehensive samples, where pediatric patients were included, were also included and analyzed. Of note, articles were not excluded based on country of origin, year of publication, type, and stage of cancer, or in relation to the procedures adopted for treatment/therapy.

The methodological process of this scoping review consisted of a literature search in four electronic databases: Lilacs, PubMed, Scielo, Web of Science, and SPORTDiscus. The following Boolean operators and keywords were used to perform the search: "physical activity" OR "physical exercise" OR "motor activity" AND cancer* OR leukemia* OR oncologic* OR chemotherapy* AND teenager* OR adolescent* OR student* OR young* OR youth* OR juvenile* OR survivor* OR pediatric* AND barrier* AND NOT adult* OR rat* OR mouse* OR animal*. Searches were conducted on $11 / 2020$ covering original studies. A detailed description of the strategies adopted throughout can be found elsewhere (Supplement 2). To avoid missing articles of interest, a manual search of the reference lists was also carried out.

\section{Assessment, selection, and data extraction}

Articles search, selection, and evaluation as well as the analysis of the articles included (i.e., title, abstract, and full article reading) were carried out by two researchers (DU and LS). In cases of disagreement between the two evaluators, a third researcher, previously selected, was responsible for the eligibility decision (JG).

Data extraction and organization were conducted by the principal investigator using an Excel spreadsheet. The data were organized in four domains: 1) article identification (e.g., place of study, year of data collection, sample size, age group, and sex);2) information about the methods (e.g., characteristics of the study, intervention, and assessment tools); 3) information about the results (e.g., main measures and barriers) and 4) Study limitations (e.g., main difficulties).

After selecting, evaluating, and extracting data from the studies found in the search, we decided to remove the risk of bias instrument, as four studies were classified as observational. Although organizations such as the Cochrane Collaboration propose and updated assessment tools for non-observational studies, currently they do not present a valid instrument for verifying the risk of bias in observational studies.

\section{Results}

The data obtained from the selected studies are shown in Figure 1. Briefly, the search in the databases yielded 608 studies, and after the initial screening, 51 studies were selected for the second stage (i.e., abstracts checking). Forty out of 51 studies were excluded, and therefore, 11 studies were selected for full-text reading. Because of the inclusion criteria adopted an additional seven studies were excluded ( 2 studies did not fit the design criteria and 4 studies due to the age of the participants included). Thereby, the descriptive synthesis of the present review comprised five studies ${ }^{21-25}$.

\section{Characteristics of participants and studies}

The selected articles were published between 2010 and 2015, with all articles coming from high-income countries (i.e., United States of America ${ }^{21}$; Canada ${ }^{22,24}$; Germany $^{23}$; Australia ${ }^{25}$ ). The sample size ranged from $40^{23}$ to $105^{21}$ participants, involving individuals between the ages of 4 and 20 years old (Table 1). Three studies included children and adolescents ${ }^{22,23,25}$, whilst the other two articles involved only adolescent ${ }^{22,24}$, Leukemia $^{21,22,24,25}$ and bone tumor ${ }^{23}$ were the most prevalent types of cancer in the samples. 


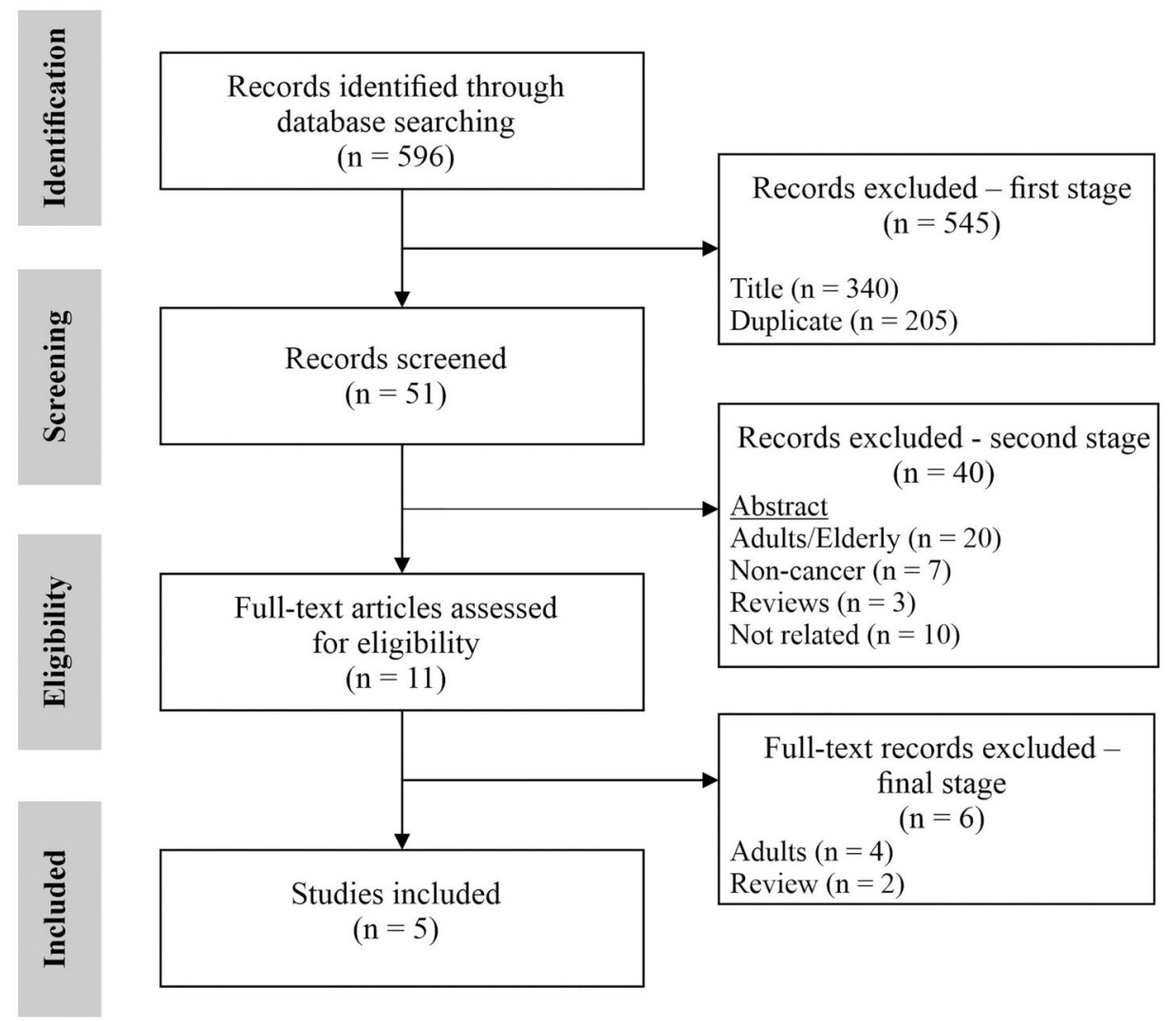

Figure 1 - Flow diagram of study selection.

Table 1 - Location identification and characteristics of the study samples.

\begin{tabular}{|c|c|c|c|c|c|}
\hline Reference & $\begin{array}{l}\text { City (year of data } \\
\text { collection) }\end{array}$ & $\begin{array}{l}\text { Sample } \\
\text { size }\end{array}$ & $\begin{array}{r}\text { Age } \\
(\bar{x})\end{array}$ & $\begin{array}{c}\text { Female } \\
(\%)\end{array}$ & Cancer type \\
\hline $\begin{array}{l}\text { Gilliam et al. } \\
2013\end{array}$ & $\begin{array}{l}\text { Birmingham, United States } \\
\text { of America (2010-2011) }\end{array}$ & 105 & $\begin{array}{c}8-16 \\
(12.3)\end{array}$ & 51 & $\begin{array}{l}\text { Leukemia, Central Nervous System Tumor, Soft Tissue Sarcoma, Non- } \\
\text { Hodgkin's Lymphoma, Kidney Tumor, Neuroblastoma, Hodgkin's } \\
\text { Lymphoma, Osteosarcoma, Other }\end{array}$ \\
\hline $\begin{array}{l}\text { Wright et al. } \\
2013\end{array}$ & Hamilton, Canada (2013) & 96 & $\begin{array}{l}13-18 \\
(16.0)\end{array}$ & 39 & Leukemia, Solid Tumor, Lymphoma, Central Nervous System Tumor \\
\hline $\begin{array}{l}\text { Götte et al. } \\
2014\end{array}$ & $\begin{array}{l}\text { Müenster, Germany (2011- } \\
\text { 2012) }\end{array}$ & 40 & $\begin{array}{c}4-20 \\
(13.2)\end{array}$ & 47 & $\begin{array}{l}\text { Acute Lymphoblastic Leukemia, Acute Myeloid Leukemia, Lympho- } \\
\text { ma, Bone Tumor, Ewing Sarcoma, Osteosarcoma }\end{array}$ \\
\hline Wright, 2015 & Hamilton, Canada (2015) & 80 & $\begin{array}{l}12-19 \\
(15.0)\end{array}$ & 43 & Leukemia, Lymphoma, Other \\
\hline $\begin{array}{l}\text { Mizhari et al. } \\
2020\end{array}$ & $\begin{array}{l}\text { Sydney, Australia (2017- } \\
\text { 2018) }\end{array}$ & 102 & $\begin{array}{c}8-18 \\
(12.8)\end{array}$ & 38 & $\begin{array}{l}\text { Acute Lymphoblastic Leukemia, Lymphomas, Wilms' Tumor, Neuro- } \\
\text { blastoma, Acute Myeloid Leukemia, Other }\end{array}$ \\
\hline
\end{tabular}

$\overline{\mathrm{x}}$ : Average; \%: Percentage.

All studies adopted a cross-sectional design ${ }^{21-25}$. Regarding the instruments to assess barriers to PA, it was observed that studies adopted either the use of questionnaires $^{21,22,24,25}$ or semi-structured interviews ${ }^{22,23}$. Additional data collected included: anthropometric measurement with bioimpedance, blood pressure, and the use of an oximeter ${ }^{25}$ (Table 2). It was further observed a great heterogeneity regarding the moments of application of the instruments in the treatment phase $\mathrm{e}^{23}$, in the posttreatment phase $\mathrm{s}^{21,22,25}$, and both ${ }^{24}$.
For a better understanding of the results, barriers to PA were organized into four domains: individual, physical, environmental, and therapy/treatment (Table 3). Overall, 40 barriers were observed, with a greater number being classified as an individual $(\mathrm{n}=19)$ and physical $(\mathrm{n}=14)$ domains. More specifically, fatigue ${ }^{21,23-25}$ and lack of company ${ }^{22-25}$ were the most frequent barriers to PA among cancer pediatric patients. Such barriers were reported by three out of five included studies. 
Table 2 - Identification and main characteristics of the instruments for data collection.

\begin{tabular}{|c|c|c|c|}
\hline Author & Instruments for collection & Validation of instruments & $\begin{array}{l}\text { Time for } \\
\text { collection }\end{array}$ \\
\hline \multirow{9}{*}{$\begin{array}{l}\text { Gilliam et al. } \\
2013\end{array}$} & Questionnaires & & $\cong 20 \mathrm{~min}$ \\
\hline & 1- Sociodemographic & $1-\mathrm{nd}$ & \\
\hline & $\begin{array}{l}\text { 2- Common Terminology Criteria for Adverse Events - version } \\
3\end{array}$ & 2- Kappa coefficient and ICC $r=0.88-1.00$ & \\
\hline & $\begin{array}{l}\text { 3- Modified Leisure Score Index > Godin Leisure Time Exer- } \\
\text { cise Questionnaire }\end{array}$ & $3-\mathrm{r}=0.24 \mathrm{VO} 2 \mathrm{max}$ e $0.13 \mathrm{BF}, \mathrm{p}<0.01^{22}$ & \\
\hline & 4- PA scale (19 items) & 4- $\alpha=0.78$ e $r=0.81, \alpha=0.84$ (in this study) & \\
\hline & 5- PA peer support (3 items) & 5- $\alpha=0.74$ e $r=0.70, \alpha=0.88$ (in this study) & \\
\hline & 6- Perceived benefits to PA (13 items) & 6- $\alpha=0.92$ e $r=0.65, \alpha=0.71$ (in this study) & \\
\hline & 7- Perceived barriers to PA (23 items) & 7- $\alpha=0.88$ e $r=0.65, \alpha=0.86$ (in this study) & \\
\hline & 8- Self-efficacy to PA (5 items) & 8- $\alpha=0.85$ e $r=0.89, \alpha=0.70$ (in this study) & \\
\hline \multirow{9}{*}{$\begin{array}{l}\text { Wright et al. } \\
2013\end{array}$} & Questionnaires & & nd \\
\hline & $\begin{array}{l}\text { 1- Leisure Score Index of Godin Leisure-Time Exercise Ques- } \\
\text { tionnaire }\end{array}$ & $1-r=0.81$ & \\
\hline & 2- PRO Questionnaires for facilitators and barriers to PA & 2- nd & \\
\hline & 3- Fatigue Scale for Adolescents & $3-\alpha=0.87^{22}$ & \\
\hline & $\begin{array}{l}\text { 4- Amherst Health and Activity Study Student Survey - adap- } \\
\text { ted }\end{array}$ & $\begin{array}{l}\text { 4- } r=0.34 \text { e } 0.64 \text { students-parents and PA, } 0.04 \text { a } 0.21 \\
\text { students and PA }\end{array}$ & \\
\hline & Semi-structured interview & & \\
\hline & 5- Recorder & 5- nd & \\
\hline & Measures & $\begin{array}{l}\text { 6- BMI - } 70 \% \text { to } 80 \% \text { sensitivity and positive pre- } \\
\text { dictive value, } 95 \% \text { high specificity }{ }^{23}\end{array}$ & \\
\hline & $\begin{array}{l}\text { 6- Anthropometric - Clinical documents (patients) and self- } \\
\text { report (non-patients) }\end{array}$ & & \\
\hline \multirow{7}{*}{$\begin{array}{l}\text { Götte et al. } \\
2014\end{array}$} & Face to face interview & nd & $\cong 18 \mathrm{~min}$ \\
\hline & 1- Exercise values and beliefs during intensive care & & \\
\hline & 2- Barriers to exercise & & \\
\hline & 3- Motivations to exercise & & \\
\hline & 4- Encouragement of parents and doctors & & \\
\hline & Medical information & & \\
\hline & 5- Electronic patient record technology & & \\
\hline \multirow[t]{4}{*}{ Wright, 2015} & Questionnaires & & nd \\
\hline & 1- Pediatric Outcomes Data Collection & $1.1 / 1.2-\alpha=>0.80$ & \\
\hline & 1.1- Transfer and Basic Mobility & & \\
\hline & 1.2- Sports/Physical Functioning & & \\
\hline \multirow{9}{*}{$\begin{array}{l}\text { Mizhari et al. } \\
2020\end{array}$} & Questionnaires & & nd \\
\hline & 1- Sociodemographic & $1-\mathrm{nd}$ & \\
\hline & 2- Clinical variables & 2- nd & \\
\hline & $\begin{array}{l}\text { 3- Leisure Score Index of Godin Leisure-Time Exercise Ques- } \\
\text { tionnaire }\end{array}$ & $3-r=0.84$ & \\
\hline & 4- Barriers to exercise & 4- Based on ${ }^{10}$ & \\
\hline & $\begin{array}{l}\text { 5- Patient-Centered Assessment and Counseling for Exercise } \\
\text { questionnaire }\end{array}$ & $5-\alpha=>0.75^{24}$ & \\
\hline & 6- Screen time questionnaire (purpose-designed) & 6- nd & \\
\hline & Measures & & \\
\hline & 7- Aneroid sphygmomanometer (blood pressure) & 7- nd & \\
\hline
\end{tabular}


Table 2 - continued

\begin{tabular}{|c|c|c|c|}
\hline Author & Instruments for collection & Validation of instruments & $\begin{array}{l}\text { Time for } \\
\text { collection }\end{array}$ \\
\hline & 8- 6-min walk test & 8- Based on ${ }^{25-27}$ & \\
\hline & 8.1- Pulse oximeter (heart rate, oxygen saturation) & & \\
\hline & 8.2- Borg's Scale (rate of perceived exertion 1-10) & & \\
\hline & $\begin{array}{l}\text { 9- Anthropometric (bioimpedance InBody 570) and (digital } \\
\text { stadiometer and weighed to BMI) }\end{array}$ & 9- Based on ${ }^{28}$ & \\
\hline
\end{tabular}

$\alpha$ : Cronbach's alpha; ICC (r): Intraclass correlation coefficient; nd: Not described; PA: Physical Activity; BMI: Body Mass Index.

Other less frequently reported barriers included: lack of energy and bad mood ${ }^{22,23}$; bad weather ${ }^{22,23,25}$; lack of time $^{21,22,25}$; perception of PA practice as boring ${ }^{21,22}$; nausea, lack of motivation to practice, excessive medical-hospital routine ${ }^{23}$; lack of access to structures for $\mathrm{PA}^{23-25}$; pain $^{24,25}$; lack of instruction from doctors and parents, fear of others' opinion ${ }^{24}$ and lack of social support from family and friends $\mathrm{s}^{21,22,24}$ (Table 3).

\section{Discussion}

This scoping review aimed to provide an overview of reported barriers to PA in the pediatric cancer population, as well as to examine the methods/instruments used to assess such information. Among the included studies, a total of 40 different barriers to PA were reported by this population, either during or after treatment. A significant proportion of the factors negatively impacting PA participation in this population were related to the individual and physical domains. Barriers such as lack of company and fatigue were reported in four out of the five included studies. Regarding the methods used to assess barriers to PA, it was observed a great heterogeneity in terms of the instruments of data collection and forms of application, and sample inclusion criteria concerning the different types of cancers and moments of the treatment (e.g., during and/or after treatment).

The findings of the present review are somehow similar to the results observed by previous studies in non- cancer groups. For example, a systematic review with adolescents between 10 to 19 years old without cancer (n $=8.350$ ), presented that the main barriers in the individual domain are lack of company, social support from family and friends, and motivations ${ }^{15}$. However, in the same study, the physical domain such as fatigue was not reported as a barrier to PA by these adolescents.

However, after the diagnosis of cancer in pediatric individuals, a new life routine emerges, which impacts on the reduction of PA levels due to the disease itself and cancer treatment, which, although highly effective during the cancer remission process, presents short and long-term adverse effects on patients. Among the wide array of adverse effects is the increase in fatigue, deficits in cardiopulmonary function, in the immune system, and the neuromuscular system ${ }^{26}$; in addition to greater weaknesses in mobility and functional capacities, especially in females patients $^{24}$. Furthermore, patients undergoing treatment are more likely to avoid participation in PA practice, which may result in higher levels of social isolation ${ }^{27}$ and loneliness ${ }^{28}$, impacting the perception related to lack of company.

The barriers and their respective domains identified by this study are in line with the multiple levels of influence observed in the socio-ecological model of health behavior, in which different levels interact with each other to influence behavior (i.e., physical activity). The multiple levels of influences often include intrapersonal, interpersonal, organizational, community, physical environ-

Table 3 - Synthesis of barriers to PA in pediatric cancer patients and survivors.

\begin{tabular}{|c|c|}
\hline Barriers & Description \\
\hline Individual & $\begin{array}{l}\text { Dislike } \mathrm{PA}^{20} \text {; find boring } \mathrm{PA}^{17,18} \text {; moodiness and lack of energy }{ }^{18,19} \text {; lack of self-discipline and skill }{ }^{18} ; \text { lack of time }{ }^{17,18,21} \text {; } \\
\text { lack of company }{ }^{18-21} \text {; lack of instruction from doctors and parents }{ }^{20} ; \text { lack of social support from family and friends }{ }^{17-18-20} ; \\
\text { lack of knowledge on how to be physically active and teasing friends during } \mathrm{PA}^{18,21} \text {; someone told them not to exercise and } \\
\text { lack of self-awareness about exercise appearance }{ }^{18} ; \text { fear of others opinion }{ }^{20} \text {, experiences that diminished the pleasure if prac- } \\
\text { ticing PA, lack of reason for PA and school lessons }{ }^{19} \text {, rather watch } \mathrm{TV}^{21} \text {. }\end{array}$ \\
\hline Physical & $\begin{array}{l}\text { Fatigue }^{17,19-21} \text {; pain } \\
\text { blems, lack of physical fitness, difficulties in dynamic movements, and limitations due to the tumor site, drowsiness }{ }^{19} \text {; over- } \\
\text { weight }^{18} \text { and general health }{ }^{20} \text {. }\end{array}$ \\
\hline Environmental & Lack of space to practice PA and lack of sports equipment ${ }^{19,21}$; bad weather ${ }^{18,19,21}$; no gym access ${ }^{21}$. \\
\hline $\begin{array}{l}\text { Related to treatment/ther- } \\
\text { apy }\end{array}$ & Time of treatment and medical-hospital routines ${ }^{19}$; late-effects ${ }^{21}$ \\
\hline
\end{tabular}

PA: Physical Activity. 
ment, and policy ${ }^{29}$. Despite the domains are interrelated, recognizing barriers by categories seems to be coherent to promote actions and adequate incentives suitable for a more active lifestyle in pediatric cancer patients or survivor $^{30}$. A multidisciplinary approach that goes beyond the hospital environment, which is safe, feasible, and adaptable to the health conditions of patients and the routine of their respective parents/guardians ${ }^{31,32}$.

Previous studies have shown that PA interventions in this population are highly promising since they reflect improvements in fatigue ${ }^{33}$, cardiac function ${ }^{34}$, muscle strength $^{35}$, and do not compromise the immune system, consequently improving patients' and survivors' quality of life $^{36}$. In addition, the social support from family and friends represents a motivation factor for engaging in practices within the hospital ${ }^{37}$. Similarly, social support from the community and sports groups ${ }^{38}$ can also approximate them to PA practice, which can provide interaction and feelings of greater independence for those involved ${ }^{39}$.

\section{Study limitations}

Although research on PA for pediatric cancer patients and survivors has expressed positive effects and significant advances in the past 15 years, the area still faces important limitations and biases, such as the reduced use of objective assessments and sample diversity in terms of age group, sex, stages of treatment, post-treatment and types of cancers ${ }^{12}$. This scoping review confirms these limitations, also identifying the wide use of different questionnaires, some specific for the pediatric oncology population and others not; in addition, the sample diversity, previously mentioned, makes it difficult to make comparisons and generalizations, since the actions and strategies to promote PA may have different characteristics for various oncological groups and periods of treatment or posttreatment.

Another point identified by this scoping review was the paucity of studies regarding barriers to PA during and after pediatric cancer treatment. Our literature search identified only five studies. According to a previous study, researchers have focused on investigating motor function, fatigue, well-being, and quality of life $\mathrm{e}^{40}$, in addition to recognizing the difficulties in developing research with this population, such as the period of treatment, social isolation, arduous medical-hospital routine, state of vulnerability and the overprotection of health teams and family member ${ }^{41}$.

The strengths of this study lie in the strong methodology used to search for the articles, the design that followed the principles recommended by PRISMA. In addition, to the best of our knowledge, this is a recent study that attempts to summarize the current literature on this theme.

Future studies should adopt the mix-methods approach, longitudinal design, and well-structured valid questionnaires to be used in pediatric cancer patients and survivors. In addition, semi-structured interviews implemented alongside visual participatory research methods such as photo-elicitation ${ }^{42}$ can help shed light on the reality of these participants and should be used to foster the qualitative uniqueness of the topic. It is noteworthy that offering several means of data collection, such as telephone, e-mail, and remote interviews can facilitate participation.

The most prevalent barriers were those of personal and physical characteristics, which favors practical implications for training health professionals to work with guidelines for pediatric cancer patients and their families on the benefits of a more active lifestyle and, consequently, impact on the health and quality of life during and after cancer treatment.

\section{Conclusion}

The available evidence suggests that the greatest number of barriers to PA practice in pediatric cancer patients and survivors is found in the individual and physical domains, such as lack of company and fatigue, domains that are also enhanced by the treatment itself. In order to overcome such barriers, health professionals should advise and offer patients and their families the possibility of adopting a more active lifestyle during treatment. There is compelling evidence of the benefits of PA during and after cancer treatment, highlighting not only the benefits of such behavior on symptoms of the diseases (e.g., fatigue) but more important on quality of life.

\section{Acknowledgments}

We are gratefully the Postgraduate Program in Movement Sciences, São Paulo State University, National Council for Scientific and Technological Development (CNPq), and Coordination for the Improvement of Higher Education Personnel (CAPES).

\section{References}

1. Curado MP, Edwards B, Shin HR, Storm H, Ferlay J, Heanue $\mathrm{M}$, et al. Cancer incidence in five continents IX. Lyon, IARC; 2007. Available from: https://ci5.iarc.fr/CI5I-X/ Pages/download.aspx [Accessed 5th March 2018].

2. Instituto Nacional de Câncer José de Alencar Gomes da Silva. Estimativa 2018: incidência de câncer no Brasil. Rio de Janeiro, Coordenação de Prevenção e Vigilância INCA; 2017. Available from: http://www.epi.uff.br/wp-content/ uploads/2013/08/estimativa-incidencia-de-cancer-no-brasil2018.pdf [Accessed 18th September 2018].

3. World Health Organization. Global recommendations on physical activity for health. Geneva, World Health Organization; 2010. Available from: https://apps.who.int/iris/han dle/10665/44399 [Accessed 21st January 2019]. 
4. World Health Organization. Guide to cancer early diagnosis. Geneva, World Health Organization; 2017. Available from: https:/www.who.int/cancer/publications/cancer_early_diag nosis/en/ [Accessed 15th January 2019].

5. Islami F, Sauer AG, Miller KD, Siegel RL, Fedewa SA, Jacobs EJ, et al. Proportion and number of cancer cases and deaths attributable to potentially modifiable risk factors in the United States. CA Cancer J Clin. 2018;68:31-54.

6. Reilly JJ, Ventham JC, Ralston JM, Donaldson M, Gibson B. Reduced energy expenditure in preobese children treated for acute lymphoblastic leukemia. Pediatric Res. 1998;44:557-62.

7. Oeffinger KC, Mertens AC, Sklar CA, Kawashima T, Hudson MM, Meadows AT, et al. Chronic health condition in adult survivors of childhood cancer. $N$ Engl J Med. 2006;355:1572-82.

8. Wilson CL, Stratton K, Leisenring WL, Oeffinger KC, Nathan PC, Wasilweski-Masker K, et al. Decline in physical activity level in the childhood cancer survivor study cohort. Cancer Epidemiol Biomarkers Prev. 2014;23(8):1619-27.

9. Klika R, Tamburini A, Galanti G, Mascherini G, Stefani L. The role of exercise in pediatric and adolescent cancers: a review of assessments and suggestions for clinical implementation. J Funct Morphol Kinesiol. 2018;3(7):1-19.

10. Arroyave WD, Clipp EC, Miller PE, Jones LW, Ward DS, Bonner MJ, et al. Childhood cancer survivor's perceived barriers to improving exercise and dietary behaviors. Oncol. Nurs. Forum. 2008;35(1):121-30.

11. Winter C, Müller C, Hoffmann C, Boos J, Rosenbaum D. Physical activity and childhood cancer. Pediatr Blood Cancer. 2010;54:501-10.

12. Zhang FF, Saltzman E, Must A, Parsons SK. Do childhood cancer survivors meet the diet and physical activity guidelines? A review of guidelines and literature. Int $\mathrm{J}$ Child Health Nutr. 2012;1(1):44-58.

13. Sallis JF, Hovell MF. Determinants of exercise behavior. Exerc Sport Sci Rev. 1990;18:307-30.

14. Yelton L, Forbis S. Influences, and barriers on physical activity in pediatric oncology patients. Front Pediatr. 2016;4 (131):1-9.

15. Rech CR, Camargo EM, Araujo PAB, Loch MR, Reis RS. Perceived barriers to leisure-time physical activity in the Brazilian population. Rev Bras Med Esporte. 2018;24 (4):303-9.

16. Ross WL, Le A, Zheng DJ, Mitchell H, Rotatori J, Li F, et al. Physical activity barriers, preferences, and beliefs in childhood cancer patients. Support Care Cancer. 2018;26 (7):2177-84.

17. Nogueira HS, Lima WP. Câncer, sistema imunológico e exercício físico: uma revisão narrativa. Corpoconsciência. 2018;22(1):40-52.

18. Martinic MK, Pieper D, Glatt A, Puljak L. Definition of a systematic review used in overviews of systematic reviews, meta-epidemiological studies, and textbooks. BMC Medi Res Methodol. 2019;19:203.

19. Sucharew H, Macaluso M. Methods for research evidence synthesis: the scoping review approach. J Hosp Med. 2019;14(7):416-8.
20. Liberati A, Altman DG, Tetzlaff J, Mulrow C, Gotzsche PC, Ioannidis JPA, et al. The PRISMA statement for reporting systematic reviews and meta-analyses of studies that evaluate health care interventions: explanation and elaboration. PLoS Medicine. 2009;6(7):1-28.

21. Gilliam MB, Madan-Swain A, Whelan K, Tucker DC, Demark-Wahnefried W, Schwebel DC. Cognitive influences as mediators of family and peer support for pediatric cancer survivors' physical activity. Psychooncology. 2013;22 (6):1361-8

22. Wright M, Bryans A, Gray K, Skinner L, Verhoeve A. Physical activity in adolescents following treatment for cancer: influencing factors. Leuk Res Treatment. 2013;2013:1-7.

23. Götte M, Kesting S, Winter C, Rosenbaum D, Boss J. Experience of barriers and motivations for physical activities and exercise during treatment of pediatric patients with cancer. Pediatr Blood Cancer. 2014;61:1632-7.

24. Wright M. Physical activity participation and preferences: developmental and oncology-related transitions in adolescents treated for cancer. Physiother Can. 2015;67(3):292-9.

25. Mizhari D, Wakefield CE, Simar D, Ha L, McBride J, Field $\mathrm{P}$, et al. Barriers and enablers to physical activity and aerobic fitness deficits among childhood cancer survivors. Pediatr Blood Cancer. 2020,67:e28339.

26. Huang TT, Ness KK. Exercise interventions in children with cancer: a review. Int J Pediatr. 2011;2011:1-11.

27. Barr RD, Ferrari A, Ries L, Whelan J, Bleyer A. Cancer in adolescents and young adults: a narrative review of the current status and a view of the future. JAMA Pediatr. 2016;170(5):495-501.

28. Götte M, Taraks S, Boos J. Sports in pediatric oncology: the role(s) of physical activity for children with cancer. J Pediatr Hematol Oncol. 2014;36:85-90.

29. Martínez-Andrés M, Bartolomé-Gutiérrez R, RodríguezMartín B, Pardo-Guijarro MJ, Garrido-Miguel M, MartínezVizcaíno V. Barriers, and facilitators to leisure physical activity in children: A qualitative approach using the socioecological model. Int J Res Public Health. 2020;17:3033.

30. Brasil. Guia de Atividade física para a população brasileira. Brasília, Ministério da Saúde; 2021. Available from: https:// aps.saude.gov.br/biblioteca/visualizar/MjA1MA== [Accessed 08th August 2021].

31. Munsie C, Ebert J, Joske D, Ackland T. The benefit of physical activity in adolescents and young adult cancer patients during and after treatment: a systematic review. J Adolesc Young Adult Oncol. 2019;8:512-24.

32. Guimarães JAC. Fatores sociodemográficos, ambientais, barreiras e facilitadores à prática de atividade física de lazer de pacientes pediátricos oncológicos. Rio Claro, São Paulo. Dissertação [Mestrado em Ciências da Motricidade], Universidade Estadual Paulista Júlio de Mesquita Filho, Rio Claro; 2019.

33. Djik-Lokkart EM, Steur LMH, Braam KI, Veening MA, Huisman J, Takken T, et al. Longitudinal development of cancer-related fatigue and physical activity in childhood cancer patients. Pediatr Blood Cancer. 2019;66:e27949.

34. Morales JS, Santana-Sosa E, Santos-Lozano A, Baño-Rodrigo A, Valenzuela PL, Rincón-Castanedo C, et al. Inhos- 
pital exercise benefits in childhood cancer: A prospective cohort study. Scand J Med Sci Sports. 2019;30:126-34.

35. Fiuza-Luces C, Padilla JR, Soares-Miranda L, Santana-Sosa E, Quiroga JV, Santos-Lozano A, et al. Exercise intervention in pediatric patients with solid tumors: the physical activity in pediatric cancer trial. Med Sci Sports Exerc. 2017;49(2):223-30.

36. Patti A, Paoli A, Bianco A, Palma A. Pediatric exercise programs in children with hematological cancer: a systematic review. EJSS Journal. 2013;1(2):71-86.

37. Thorsteinsson T, Schmiegelow K, Thing LF, Andersen LB, Helms AS, Ingersgaard MV, et al. Classmates motivate childhood cancer patients to participate in physical activity during treatment: A qualitative study. Eur J Cancer Care. 2019;28:e13121.

38. Gilliam MB, Schwebel DC. Physical activity in child and adolescent cancer survivors: a review. Health Psychol Rev. 2013;7(1):92-110.

39. Spreafico F, Murelli M, Timmons BW, Massimino M, Barr R. Sport activities and exercise as part of routine cancer care in children and adolescents. Pediatr Blood Cancer. 2019;66:1-6.

40. Shank J, Chamorro-Viña C, Guilcher GMT, Langelier DM, Schulte F, Culos-Reed N. Evaluation tools for physical activity programs for childhood cancer: a scoping review. J Pediatr Oncol Nurs. 2020;37(3):163-79.

41. Wright MJ, Ness, K. Rehabilitation and exercise. In: Bleyer A, Barr R, Ries L, Whelan J, Ferrari A (eds). Cancer in adolescents and young adults. 2nd ed. Switzerland, Springer International Publishing AG; 2017. p. 651-66.
42. Sebastião E, Gálvez PAE, Bobbitt J, Adamson BC, Schwingel A. Visual and participatory research techniques: photoelicitation and its potential to better inform public health about physical activity and eating behavior in underserved populations. J Public Health. 2016;24:3-7.

\section{Supplementay Material}

Supplement 1 - Preferred Reporting Items of Systematic Review and Meta-analyzes - PRISMA20 and registered in the International Prospective Register of Systematic Reviews (CRD42018090447).

Supplement 2 - Supporting information.

\section{Corresponding author}

Jean Augusto Coelho Guimarães, Universidade Estadual Paulista, Instituto de Biociências, Programa de PósGraduação em Ciências da Motricidade, Departamento de Educação Física, Rio Claro, SP, Brazil.

E-mail: jean13ef@gmail.com.

Manuscript received on March 19, 2021

Manuscript accepted on September 27, 2021

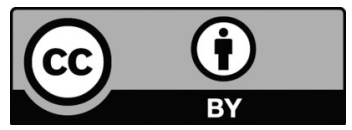

Motriz. The Journal of Physical Education. UNESP. Rio Claro, SP, Brazil - eISSN: 1980-6574 - under a license Creative Commons - Version 4.0 